\title{
Thailand top destination for medical tourists
}

B umrungrad International Hospital in Bangkok, Thailand, can feel like a shopping mall or five-star hotel. It offers 21 VIP suites and the mezzanine has a McDonald's. On the floor below, people line up to buy lattes and Americanos from a Starbucks.

Sitting nearby with coffees, a father and son from Oman silently faced each other in the lobby. They had been in Bangkok for 50 days already, travelling to Thailand to seek treatment for the father's prostate cancer.

"Some friends at home told us about this hospital," said the son, declining to give their names. "They said it is very good."

The largest private hospital in Southeast Asia, Bumrungrad is the unofficial leader of medical tourism in Thailand, itself the most popular destination for medical travellers in the world, though accurate data on this fast-growing industry remain elusive.

The Ministry of Public Health claimed Thailand received 2.5 million medical tourists last year, but medical tourism directories, like Novasans.com, consider the true number to be fewer than 700000 patients.

Singapore and India are the next leading destinations, but data for these countries are also unclear, say industry analysts. Together these three countries account for an estimated $80 \%$ of the global medical tourism market, and Thailand alone for about $40 \%$.

"Why is Thailand so popular? It's because of the Thai health care system. It's advanced and affordable, and these are the two most important criteria for would-be medical tourists," said Adele Kulyk, CEO of Saskatchewan-based Global Healthcare Connections Inc., an agency that arranges patient travel to Asia and Central America.

Assessing its own credentials as an international medical hub in late 2010, the Thai government noted it led its Asian competitors on service, matched India on cost and Singapore on quality

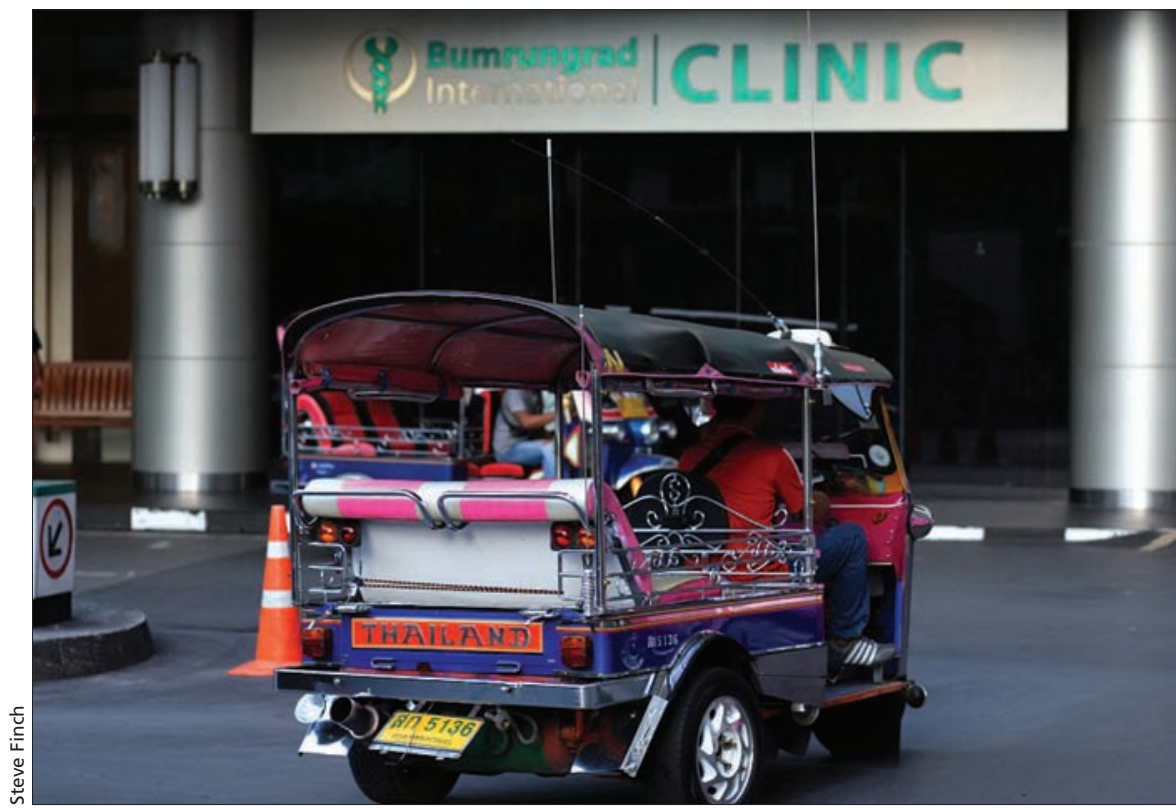

Bumrungrad International Hospital in Bangkok is the largest private hospital in Southeast Asia and the unofficial leader of medical tourism in Thailand.

of staff, but fell short on medical hardware compared to nearby Singapore.

Thailand and Singapore each had 13 hospitals accredited by Joint Commission International, an organization that promotes rigorous standards of care in more than 90 countries. In 2002, Bumrungrad became the first hospital in Asia to meet the standard. Over the past three years, 17 more Thai facilities received the endorsement, compared to Singapore's nine.

Cost is where Thailand really excels, though, said Kulyk. For heart bypass surgery, Bumrungrad offers a package including a week's stay for around $\$ 19000$, according to its website, compared to at least US\$80 000 in the US for a patient without health insurance.

Although heart surgery costs much less in Canada, wait times mean patients are increasingly seeking treatment overseas, said Kulyk, who started Global Healthcare Connections after a close friend died of cancer following a late diagnosis.

"Thailand isn't as popular [with Canadians] as Mexico, the Cayman Islands, South Korea and other coun- tries," she said, citing the lengthy travel time. "But Thailand got a head-start on these others, so they've had a number of years to work very hard on this program and to understand the needs of the international traveler."

Part of Thailand's medical tourism success is due to its wider popularity as a holiday destination. Bangkok is expecting 16 million foreign visitors this year, more than any other city in the world. More than 900000 of these are expected to seek medical care as ever larger numbers from across the globe experience Thai hospitals and clinics first-hand.

In the Middle East, Thailand's reputation for quality health care is already well known, a side-effect of tragedy in the US. After 9/11, many people in Arab states stopped travelling to Europe and North America for treatment amid discrimination and visa problems and instead took the sevenhour flight in the other direction to Bangkok, said Kenneth Mays, Bumrungrad's marketing director.

"Then it started really booming," he said, as the number of Middle Eastern 
patients at the hospital soared 12-fold to 120000 visitors per year in the decade after $9 / 11$.

More recently, overseas delegations have toured Bumrungrad in a bid to emulate their model, but Mays said these visits have been stopped to retain competitive advantage.

"We found that, for example, [some groups] were touring our facility and taking pictures, measuring walls and going back and trying to create places to compete with us," he said.
As the multibillion-dollar medical tourism market develops, other Asian countries are expected to remain Thailand's main competitors with patients tipped to increasingly favour destinations closer to home, said Mays and Kulyk.

Meanwhile, India has announced a target of one million overseas patients by 2015 . Singapore is also hoping to boost medical tourism. Soo Siew Keong, director of business development enrichment at the Singapore Tourism Board, said his office's recent programs include a prototype ward with the Raffles Medical Group for Middle Eastern patients and a VISA partnership offering medical concierge services to visiting Indonesian cardholders.

"With additional private health care capacity coming on stream in the next few years, the [Singapore] industry has made efforts to reach out to key markets," he said. - Steve Finch, Bangkok, Thailand

CMAJ 2014. DOI:10.1503/cmaj.109-4655 